\title{
TERT Genotyping for Evaluation of Reproduction Failure
}

\author{
NOEMI MESZAROS ${ }^{1}$, NICOLETA IOANA ANDREESCU2*, SIMONA SORINA FARCAS², ANDREEA IULIA DOBRESCU², \\ LAVINIA ELENA STELEA ${ }^{3}$, ENDRE MATHE ${ }^{1}$, ANCA PORUMB ${ }^{4 *}$, MARIA PUIU² \\ 'Vasile Goldis Faculty of Medicine, Life Science Department, 86 Liviu Rebreanu Str, 310414, Arad, Romania \\ 2Victor Babes University of Medicine and Pharmacy, Discipline of Genetics, 2 Eftimie Murgu Sq., 300041, Timisoara, Romania \\ ${ }^{3}$ Victor Babes University of Medicine and Pharmacy, Department of Obstetrics-Gynecology, Timisoara, Romania, 2 Eftimie Murgu \\ Sq., 300041, Timisoara, Romania \\ 4University of Medicine and Pharmacy, Faculty of Dentistry, 10, 1 Decembrie Str., 410068, Oradea, Romania
}

\begin{abstract}
Reproduction failure was associated with advanced maternal age, but the mechanism underlying this events were still under debate. Telomere length of the oocytes has been correlated with the embryo quality, the chance of successful pregnancy and further development of the conception. The study included a total of 35 women with pregnancy loss and 35 fertile proven females. Cytogenetic analysis of the chorionic villi was done for all the women from the study lot that exhibit a pregnancy loss. The TERT rs2736100 genotyping was performed after enrollment of the last patient, and the laboratory staff was blinded to the patients' data. Comparing the frequency of the genotypes in the study groups was found that in the study lot the $A C$ genotypes was the most frequent (51.4\%), while in the control lot the AA genotypes was the prevalent genotype (60\%). The difference between genotypes frequencies in the study lot and the control lot were statistically significant. To our knowledge, this is the first study addressing the potential role of a single nucleotide variant in TERT gene in relation with miscarriage.
\end{abstract}

Keywords: TERT gene, miscarriage, rs2736100

Reproduction failure was associated with advanced maternal age, but the mechanism underlying this events were still under debate. Almosta century has passed since the advanced maternal age was associated with an increased risk for having a child with Down syndrome (DS), but still the molecular mechanisms of this association are undecipherable[1].

There is a clear evidence that fertility in women declines after 35 years and the conceptions in females over 35 years old is prone to miscarriage and/or aneuploid offspring at a higher rate than in females under 35 years old [2]. As aneuploid oocytes and embryos usually undergo apoptosis at a an early gestational age, it will lead to infertility, and in some cases if escaping the apoptotic mechanisms will end up in a later pregnancy failure or give rise to offspring with genetic imbalances $[3,4]$.

For explaining the role of advanced maternal age on aneuploidy appearance, Warburton hypothesized that biological aging is differing among women that have the same chronological age and the frequency of trisomy if the fetuses of those females is rather correlated with the biological age than on their chronological age [5].

The biological age was correlated with the length of telomeres [6]. Telomeres are defined as chromosomes ends containing repetitive sequences that play an important role in maintaining chromosome integrity and protect chromosome from degradation and end-to-end fusion. After each cell division telomere are shortened and this mechanism is reasonable for cell senescence [7]. It was showed that shortened telomere leads to cell death, decreased recombination rate, meiotic arrest, missegregation, chromosomal instability and are associated with reduced embryonic viability [8].

Telomeres plays an important role in meiotic recombination and pairing of homologous chromosomes during meiosis and was found that shortening of telomeres leads to formation of oocytes with reduced synapsis, abnormal chromosome alignment and impaired embryonic development $[2,9]$. The effects of telomere shortening are: aneuploidies, non-reciprocal translocations and DNA damage [8].

A previous study using animal models suggested that shortened telomeres from germ cells may cause abnormal cleavage and impaired development of the embryo [10].Telomere length of the oocytes has been correlated with the embryo quality, the chance of successful pregnancy and further development of the conception $[9,11]$.

The most important components of the telomerase complex are telomerase reverse transcriptase (TERT) which is a catalytic subunit of the telomerase and the telomerase RNA component (TERC) [12]. A variant in the second intron of TERT (hTERT) gene, rs2736100, play an important role in hTERT synthesis and activation. This variant was reported to be correlated with susceptibility to different types of cancer [13].There are studies reporting that variant rs $2736100 \mathrm{~T}>\mathrm{G}$ of the TERT gene was found to be correlated with shortened telomere length in several types of cancers, while in other studies no association between telomere length and rs2736100 was found $[14,15]$.

The browsing of the literature showed that there are very few studies that have been evaluate the TERT variants in correlation with reproductive fitness.

\section{Experimental part}

Materials and methods

Study subjects

The study was done in the Genetic Laboratory from Dumitru Popescu Hospital Timisoara and in the Genomic Medicine Center from the University of Medicine and Pharmacy Victor Babes Timisoara and included a total of 35 women with pregnancy loss and and 35 fertile proven females. For each participant in the study an informed consent was obtained and the study comply the ethical regulation of the University of Medicine and Pharmacy Victor Babes Timisoara. Detailed medical and family history was recorded. For each woman included in the study were done a gynaecological exam and clinical investigation to

\footnotetext{
*email: nicollandreescu@yahoo.com; ancaporumb@yahoo.com
} 
exclude possible infection, reproductive tract malformations, endocrine or haematological disorder etc. The control group included women having at least one child and no history of infertility or miscarriages.

\section{Specimen preparation and karyotyping}

Cytogenetic analysis of the chorionic villi was done for all the women from the study lot that exhibit a pregnancy loss. The chorionic villi were obtained from the products of conception after the curettage of uterine cavity and placed in transport medium. Chorionic villi were cleaned in Dulbecco's Modified Eagle Medium (Life Technologies). Cells were cultured in three flasks in Chang Medium D (Irvine Scientific). After 5-6 days, cells were harvest according the standard protocol. For each case at least 10 metaphases were analyzed.

\section{TERT genotyping}

From each patient that met the inclusion criteria were collected $2 \mathrm{ml}$ venous blood in EDTA tubes. Genomic DNA was extracted from EDTA blood using Mag Core instrument and Mag Core Genomic DNA whole blood kit (RBC Bioscience). The TERT genotyping was performed after enrollment of the last patient, and the laboratory staff was blinded to the patients' data. TERT rs2736100 identification was performed by using TaqMan Genotyping Assay for Allelic Discrimination and TaqMan ${ }^{\circledR}$ PCR Master Mix (Applied Biosystems) according to the protocol provided by the producer. Allelic discrimination was carried out on QuantStudio 7 Real-Time PCR System with the following parameters: $95^{\circ} \mathrm{C}$ for $10 \mathrm{~min}, 40$ cycles of $92^{\circ} \mathrm{C}$ for $15 \mathrm{~s}$ and $60^{\circ} \mathrm{C}$ for $1 \mathrm{~min}$. TERT genotyping was done in the presence of two controls, AL-1 (A) and AL-2 (C). Genotypes were determined by measuring allele-specific fluorescence using the QuantStudio 7 software for allelic discrimination (Applied Biosystems).

\section{Statistics}

Statistical analysis was performed by using IBM SPSS Statistics 23 program and we considered significant a twotailed $p$ value $<0.05$. To describe the cohort, we tested the data normality distribution. We calculated expected value and we considered a cut-off point of 5 . Chi2 test or Fisher's Exact test were used to compare proportions.

\section{Results and discussions}

The study included two groups, one formed by 35 patients with pregnancy loss and 35 females with no history of reproduction failure. Descriptive statistic is presented in table 1.

Three genotypes were found for each study lot: $A A, A C$ and CC. We had analyzed the TERT genotypes frequencies for each study lot and the results are presented in table 2 .

Comparing the frequency of the genotypes in the study groups was found that in the study lot the AC genotypes was the most frequent (51.4\%), while in the control lot the AA genotypes was the prevalent genotype (60\%). The difference between genotypes frequencies in the study lot and the control lot were statistically significant $(p=0.001)$

For the study lot, 24 of the aborted fetuses presented normal karyotype, while 11 cases had numerical chromosomal aberrations (table 3).

\begin{tabular}{|l|r|r|r|r|r|}
\hline \multicolumn{7}{|c|}{ Descriptive Statistics } \\
\hline & \multicolumn{1}{|c|}{ N } & Minimum & Maximum & \multicolumn{1}{c|}{ Mean } & Std. Deviation \\
\hline Gestational age & 35 & 6.0 & 14.0 & 8.400 & 1.9433 \\
\hline Matemal age & 35 & 18.0 & 41.0 & 31.829 & 5.3824 \\
\hline Number of pregnancies & 35 & 1.0 & 5.0 & 2.057 & 1.0556 \\
\hline Valid N (listwise) & 35 & & & & \\
\hline
\end{tabular}

\begin{tabular}{|l|l|c|c|c|c|}
\hline \multicolumn{7}{|c|}{ TERT Genotype for study lot } \\
\hline \multirow{2}{*}{ Valid } & AA & 7 & 20.0 & 20.0 & 20.0 \\
\cline { 2 - 7 } & AC & 18 & 51.4 & 51.4 & 71.4 \\
\cline { 2 - 7 } & CC & 10 & 28.6 & 28.6 & 100.0 \\
\cline { 2 - 7 } & Total & 35 & 100.0 & 100.0 & \\
\hline \multirow{7}{*}{ Valid } & AA & 21 & 60.0 & 60.0 & 60.0 \\
\hline & AC & 12 & 34.3 & 34.3 & 94.3 \\
\hline & CC & 2 & 5.7 & 5.7 & 100.0 \\
\hline & Total & 35 & 100.0 & 100.0 & \\
\hline
\end{tabular}

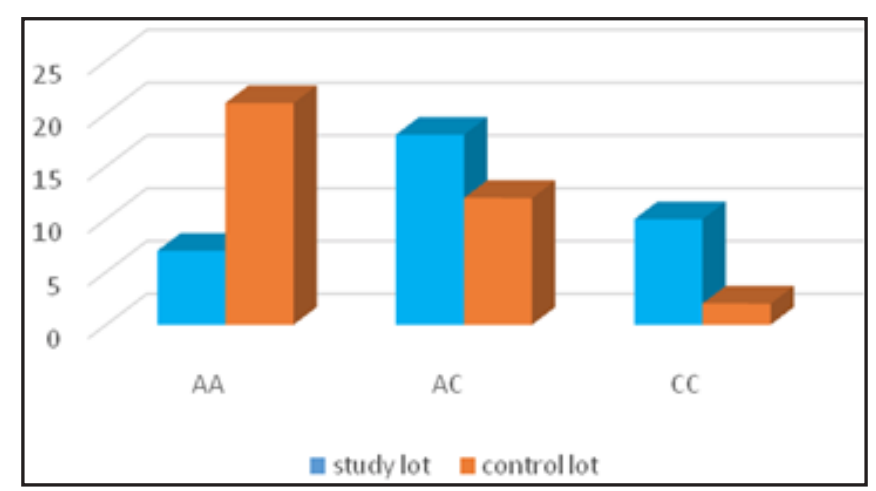

Table 1

DESCRIPTIVE STATISTICS FOR THE LOTS ANALYZED

Table 2

TERT GENOTYPE FREQUENCIES

Fig. 1. TERT genotypes distribution on the study lot as compared with the control lot 


\begin{tabular}{|c|c|c|c|c|c|}
\hline & & Frequency & Percent & Valid Percent & Cumulative Percent \\
\hline \multirow[t]{11}{*}{ Valid } & $45, \mathrm{X}$ & 3 & 8.6 & 8.6 & 8.6 \\
\hline & $46, \mathrm{XX}$ & 14 & 40.0 & 40.0 & 48.6 \\
\hline & $46, \mathrm{XY}$ & 10 & 28.6 & 28.6 & 77.1 \\
\hline & $47, \mathrm{XX},+11$ & 1 & 2.9 & 2.9 & 80.0 \\
\hline & $47, \mathrm{XX}+13$ & 1 & 2.9 & 2.9 & 82.9 \\
\hline & $47, \mathrm{XXY}$ & 1 & 2.9 & 2.9 & 85.7 \\
\hline & $47, \mathrm{XY},+21$ & 2 & 5.7 & 5.7 & 91.4 \\
\hline & $47, \mathrm{XY},+7$ & 1 & 2.9 & 2.9 & 94.3 \\
\hline & $69, \mathrm{XXY}$ & 1 & 2.9 & 2.9 & 97.1 \\
\hline & $92 . \mathrm{XXXX}$ & 1 & 2.9 & 2.9 & 100.0 \\
\hline & Total & 35 & 100.0 & 100.0 & \\
\hline
\end{tabular}

Table 3

KARYOTYPES IDENTIFIED FOR THE STUDY LOT

Analyzing the fetal karyotypes in correlation with the TERT genotype, was found that in the sub group exhibiting the AA genotype there were no abnormal fetal karyotype, in the sub group with AC genotypes 6 fetal karyotypes were aberrant, while in the subgroup with CC genotypes 5 fetal karyotypes were aneuploid.

The average maternal age in the 3 subgroups identified based on the TERT genotype was similar, no significant differences were found [31.6 years (AA) vs 31.8 year $(A C)$ vs 31.7 year $(\mathrm{CC})]$.

For the sub group with AA genotype the average number of abortions was 1.85, for the AC subgroup was 1.94, while for the CC subgroup was 2.2 miscarriages, but the difference was not statistically significant. We found no significant statistical correlation between maternal age, number of abortions and TERT genotype.

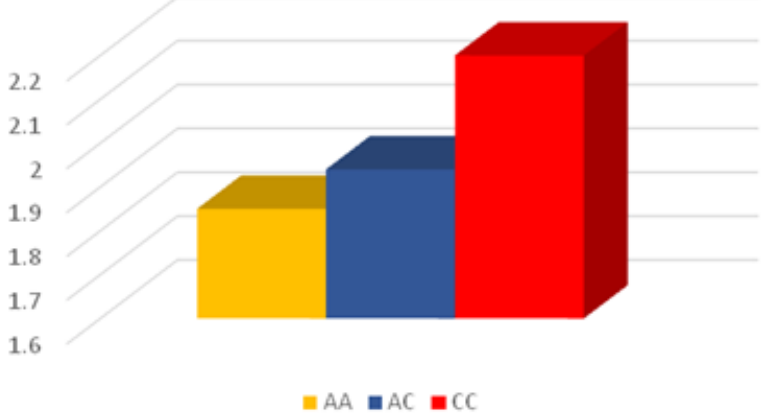

Fig. 2. Number of abortions for each TERT genotype

$A C$
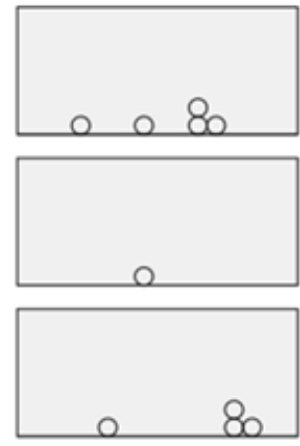

88

$20.025030 .0350 \quad 40.045$

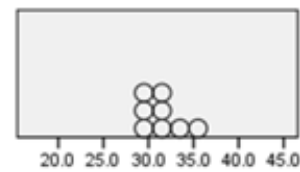

CC
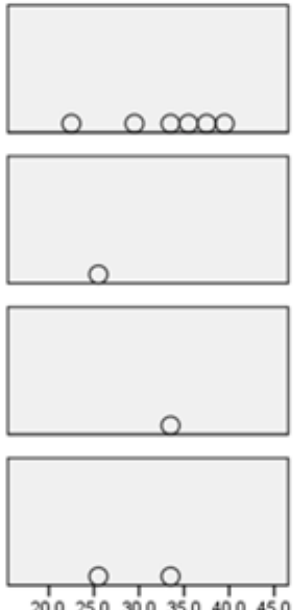

maternal age
When analyzing the genotypes for the patients having less than 3 miscarriages with those having more than 3 abortions we found a statistically significant difference of genotypes frequencies.

Telomeres play crucial roles in preservation of chromosome integrity, guiding chromosome arrangement, alignment and segregation during cell division and likely also in reproductive aging. For evaluation of the telomerase activity impact on telomere length were studied several single nucleotide polymorphisms (SNPs) in the hTERT gene. The rs2736100, rs2736122, rs4975605, rs4246742, rs10069690, rs7726159 and rs2853676 were evaluated in correlation with telomere length in different pathologies and contradictory results were obtained [16].

Telomere length has been correlated with the risk for developing different diseases such as diabetes, cardiovascular disorders, neurodegenerative conditions, infections and inflammation, cancer [17-19]. There are very few studies reporting that shortened telomere length is associated with an increased risk for miscarriage and short telomeres found in the leukocytes of couples experiencing reproduction failure could explain the infertility [11].

Browsing the available publication, we found contradictory results as regarding telomere length role in reproductive aging and the manifestations of reproductive senescence $[11,20]$.

For the women that underwent in vitro fertilization was showed that the telomeres length in the oocytes was longer for those who become pregnant as compared with the

No. $1 \bullet 2019$

AA
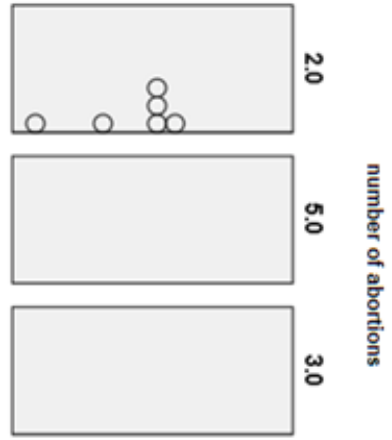

$\overrightarrow{0}$
Fig. 3. Analysis of correlation between genotype, age and number of abortions 
patients that fail to become pregnant [11]. Another study reported longer telomere length in leucocyte for women with reproduction failure that the control lot formed by women with normal fertility [21]. A possible mechanism that could explain the impact on reproduction of the telomere length is the association of short telomeres consecutive to telomerase deficiency with oocyte function alteration by acting on cumulus cells distributed over oocytes [21]. Telomerase activity in granulosa cells is supposed to have an important role in the normal development of ovarian follicles [22].

Although different studies have reported an association of short telomere length with recurrent pregnancy loss, this does not mean that longer telomeres length have no effects. This is sustained by the observation that long telomeres were reported in women with premature ovarian failure when compared with the control lot [21]. Another study that included women thatneeded ovarian stimulation treatment reported longer telomeres in the study lot than in the healthy women [23].

There is a controversy regarding the evaluation of the reproductive fitness by using the telomere length as a unique parameter. It is known that the telomerase activity can compensate the telomere shortening and thus could prevent the chromosomal fusion and maintaining the genetic integrity [24].

\section{Conclusions}

To our knowledge, this is the first study addressing the potential role of a single nucleotide variant in TERT gene in relation with miscarriage. We found a significant statistic difference of the alleles frequencies between the study lot and the lot of females with normal fertility. Also a significant correlation was found between the genotype and the more than 3 miscarriages. As the role of specific mutations that could affect the telomere length is not well clarified we consider useful to assess the rs2736100 variant in correlation with the reproduction failure. We analyzed the TERT variant rs 2736100 by an economical, versatile and highly sensitive method RT-PCR that could be used in the daily practice. Further study of TERT gene variants role in modifying telomerase expression in women with reproduction failure are still needed.

Acknowledgments. This research was done in the Center of Genomic Medicine from the Victor Babes University of Medicine and Pharmacy, Timisoara, POSCCE Project ID: 1854, cod SMIS: 48749, Center of Genomic Medicine v2, contract677/09.04.2015. The research was done thorough the collaboration established under the PNCDI III project, BM 29/2016.

\section{References}

1. RAY, A., HONG, C.S., FEINGOLD, E., GHOSH, P., BHAUMIK, P., Public Health Genomics, 19, nr. 1, 2015, p. 11-8

2. KEEFE, D.L., LIU, L., Reprod. Fertil. Dev., 21, nr. 1, 2009, p. 10

3. MUNNE, S., CHEN, S., FISCHER, J., COLLS, P., ZHENG, X., STEVENS, J., Fertil. Steril., 84, nr. 2, 2005, p. 331-5

4. LIU, L., FRANCO, S., SPYROPOULOS, B., MOENS, P.B., BLASCO, M.A., KEEFE D.L., Proc. Natl. Acad. Sci., 101, nr. 17, 2004, p. 6496-501 5. WARBURTON, D., Cytogenet Genome Res., 111, nr. 3-4, 2005, p. 266-72

6. AVIV, A., Gerontol. A. Biol. Sci. Med. Sci., 63, nr. 9, 2008, p. 979-83

7. BAIRD, D., Exp. Gerontol., 40, nr. 5, 2005, p. 363-8

8. KRIZHANOVSKY, V., XUE, W., ZENDER, L., YON, M., HERNANDO, E., LOWE, S.W., Cold Spring Harb. Symp. Quant. Biol., 73, nr. 0, 2008, p. $513-22$

9. KEEFE, D.L., FRANCO, S., LIU, L., TRIMARCHI, J., CAO, B., WEITZEN, S., Am. J. Obstet. Gynecol., 192, nr. 4, 2005, p. 1256-60

10.THILAGAVATHI, J., MISHRA, S.S., KUMAR, M., VEMPRALA, K., DEKA, D., DHADWAL, V., J. Assist. Reprod. Genet., 30, nr. 6, 2013, 793-8

11.KEEFE, D.L., LIU, L., MARQUARD, K., Cell. Mol. Life Sci., 64, nr. 2, 2007, p. 139-43

12.LU, W., ZHANG, Y., LIU, D., SONGYANG, Z., WAN, M., Exp. Cell. Res., 319, nr. 2, 2013, p. 133-41

13. FENG, L., NIAN, S., ZHANG, J., PLOS ONE., 9, nr. 1, 2014, e85719

14. KIM, J., JONES-HALL, Y.L., WEI, R., MYERS, J., QI, Y., KNIPP, G.T., Front. Genet., 4, art. 162, 2013, p. 1-6

15. LI, H., XU, Y., MEI, H., PENG, L., LI, X., TANG, J ., Oncotarget., 8, nr. 24, 2017, p. 38693-38705

16. TREFF, N.R., SU, J., TAYLOR, D., SCOTT, R.T., PLoS Genet., 7, nr. 6, 2011, e. 1002161

17. KANANEN, L., SURAKKA, I., PIRKOLA, S., SUVISAARI, J., LÖNNQVIST, J., PELTONEN, L., PLOS ONE. 5, nr. 5, 2010, e. 10826

18. SALPEA, K.D., HUMPHRIES, S.E., Atherosclerosis, 209, nr. 1, 2010, p. $35-8$

19. GRODSTEIN, F., VAN OIJEN, M., IRIZARRY, M.C., ROSAS, H.D., HYMAN, B.T., GROWDON, J.H., PLOS ONE, 3, nr. 2, 2008, e1590

20. AYDOS, S.E., ELHAN, A.H., TÜKÜN, A., Arch. Gynecol. Obstet., 272, nr. 2, 2005, p. 113-6

21. WANG, W., CHEN, H., LI, R., OUYANG, N., CHEN, J., HUANG, L., Reproduction, 147, nr. 5, 2014, p. 649-57

22. YAMAGATA, Y., NAKAMURA, Y., UMAYAHARA, K., HARADA, A., TAKAYAMA, H., SUGINO, N., Rats. Endocr. J., 49, nr. 6, 2002, p. 589-95. 23. DORLAND, M., VAN KOOIJ, R., TE VELDE, E., Maturitas, 30, nr. 2, $1998,113-8$.

24. COTTLIAR, A.S., SLAVUTSKY, I.R., Medicina, 61, 2001, p. 335-42.

Manuscript received: 6.07 .2018 